\title{
2 Temporal genetic variation in populations of the limpet 3 Cellana grata from Hong Kong shores
}

\author{
4 Wai-Chuen Ng • F. C. C. Leung - Solomon T. C. Chak \\ 5 G. Slingsby $\cdot$ Gray A. Williams
}

6

Received: 6 May 2009/Accepted: 5 October 2009

(C) Springer-Verlag 2009

8

9

10

11

12

\begin{abstract}
Variations in the relative contributions of gene flow and spatial and temporal variation in recruitment are considered the major determinants of population genetic structure in marine organisms. Such variation can be assessed through repeated measures of the genetic structure of a species over time. To test the relative importance of these two phenomena, temporal variation in genetic composition was measured in the limpet Cellana grata, among four annual cohorts over 10 years at four rocky shores in Hong Kong. A total of 408 limpets, comprising individuals from 1998, 1999, 2006 and 2007 cohorts were screened for genetic variation using five microsatellite loci. Minor but significant genetic differentiation was detected among samples from the 1998/1999 collection $\left(F_{\mathrm{ST}}=0.0023\right)$, but there was no significant differentiation among the 2006/2007 collection $\left(F_{\mathrm{ST}}=0.0008\right)$. Partitioning of genetic variation among shores was also significant in $1998 / 1999$ but not in the 2006/2007 collection, although there was no correlation between genetic and geographic distances. There was no significant difference between collections made in 1998/1999 and 2006/2007. This lack of clear structure implies a high level of gene flow, but differentiation with time may be the result of stochastic
\end{abstract}

Communicated by M. I. Taylor.

W.-C. $\mathrm{Ng}(\bowtie) \cdot$ S. T. C. Chak · G. Slingsby · G. A. Williams The Swire Institute of Marine Science and Division of Ecology \& Biodiversity, School of Biological Sciences,

The University of Hong Kong,

Pokfulam Road, Pokfulam, Hong Kong

e-mail: chuenng@hkucc.hku.hk

F. C. C. Leung

School of Biological Sciences, The University of Hong Kong, Pokfulam Road, Pokfulam, Hong Kong recruitment variation among shores. Estimates of effective population size were not high (599, 95\% C.L. 352-11397), suggesting the potential susceptibility of the populations to genetic drift, although a significant bottleneck effect was not detected. These findings indicate that genetic structuring between populations of $C$. grata in space and time may result from spatio-temporal variation in recruitment, but the potential development of biologically significant differentiation is suppressed by a lack of consistency in recruitment variability and high connectivity among shores. c.

\section{Introduction}

The transition from the pelagic larval to benthic life stage in many marine invertebrates is often the most vulnerable stage within the life cycle of a species and has been the focus of "supply-side ecology" (Underwood and Fairweather 1989). The unpredictable and often stochastic chances of survival often result in highly fluctuating numbers of successful progenies that survive to the settlement and finally recruitment stage (Hedgecock 1994). This variability is one of the crucial factors governing the on-shore population structure of many species of marine invertebrates (Morgan 2001). To complicate this picture, environmental variables also change from time to time at different spatial and temporal scales, which may further exacerbate stochastic patterns in larval supply and subsequent recruitment (Hawkins and Hartnoll 1982; Jenkins et al. 1997; McIlwain 2003; Svensson et al. 2004).

The inherent variation in larval supply is also believed to affect levels of genetic variability, which has been recorded in a variety of taxa. The term "chaotic genetic patchiness" has been used to describe genetic heterogeneity among

\begin{tabular}{lll} 
Journal : Large 227 & Dispatch : $\mathbf{1 2 - 1 0 - 2 0 0 9}$ & Pages : $\mathbf{1 3}$ \\
Article No. : $\mathbf{1 3 2 0}$ & $\square$ LE & $\square$ TYPESET \\
MS Code : MABI-D-09-00254 & $\boldsymbol{\sim}_{\text {CP }}$ & $\checkmark$ DISK \\
\hline
\end{tabular}


populations over small spatial and temporal scales (Johnson and Black 1982). Such a pattern is not, however, uncommon, even in species with planktonic larvae and high dispersal ability (Johnson and Black 1984a; Pujolar et al. 2006). Different hypotheses have been proposed to explain such apparently unpatterned genetic structure. Firstly, it has been suggested that genetic heterogeneity on small spatial/ temporal scales is a consequence of extremely large variance in individual reproductive success, which is a combined effect of high fecundity and sweepstakes-chance matching of reproductive activity with oceanographic conditions (Li and Hedgecock 1998; Lundy et al. 2000). In this case, recruits from each spawning event may inherit different proportions of the potential adult gene pool, leading to temporal genetic variance (Lenfant and Planes 2002; Bernal-Ramírez et al. 2003). Secondly, temporal variation in genetic composition may be a result of larvae being contributed from different source populations. Changes in environmental variables, such as the direction of current flow, may alter the source larval populations and hence cause genetic differentiation among recruits (Kordos and Burton 1993). Finally, selective mortality at pre- or post-settlement stages may shape on-shore population structure in a site or time specific manner, dependant on the extent or consistency of the selection force (Johnson and Black 1984a).

The likelihood for genetic patchiness to develop to biologically significant differentiation depends largely on the independence of the potential sub-populations, which is inversely related to their degree of connectivity. The impact on the overall population genetic structure could be short term, when the unmixed portion of the population is not robust enough to sustain a lasting genetic structure (Selkoe et al. 2006), or long term if genetic differentiation between cohorts accumulates over time (Maes et al. 2006).

Located on the South China coast, intertidal community structure in Hong Kong is highly dynamic, as reflected by spatial and temporal variation in settlement and recruitment (Huang 2001; Chan and Williams 2004; Yan et al. 2006). Such variation is likely to be linked with on-shore genetic structure (Li and Hedgecock 1998). The present study uses the nacellid limpet Cellana grata (Gould 1859) as a model organism to evaluate potential temporal variation in genetic structure on Hong Kong shores. C. grata is found in the mid-high shore on moderately exposed to exposed rocky shores and is a broadcast spawner (Williams and Morritt 1995). The length of the pelagic larval stage is unknown for this species but varies between 4 and 18 days in congeneric species (Bird et al. 2007). The recruitment period of C. grata is from October to July, with its peak intensity during March (Liu 1994a). In Hong Kong, C. grata lives for $3+$ years and exhibits a predictable, annual breeding cycle (Liu 1994a; Huang 2001). Most shores support populations that composed of two to three clearly identifiable cohorts, the newly settled cohort, a $1+$ year cohort that is usually the dominant cohort, and remnants of $2+$ year and very occasionally $3+$ year cohort (see Williams and Morritt 1995). These characteristics make it possible to collect multiple cohorts for temporal analysis of genetic structure in this species from different sites. As such, this makes $C$. grata an ideal animal for the present study as the evaluation of temporal genetic patterns requires repeated sampling from the same populations (Waples 1998). Most recent studies have, however, been confined to sampling only 2 or 3 years/spawning events (e.g. Virgilio and Abbiati 2006; Hepburn et al. 2009), which may limit the power to identify the presence of accumulated variation over years. The present study collected two groups of two successive yearly cohorts of C. grata, separated by 10 years from 1998 to 2007, from four shores in Hong Kong to investigate the temporal genetic structure of this limpet and to interpret possible causes of the observed patterns.

\section{Materials and methods}

Specimen collection and demographic analysis

To investigate temporal genetic structure of Cellana grata, samples were collected in 1999 and 2007 from four rocky shores in Hong Kong SAR, China. The shores represented the common settlement locations of the animal from the east to west of Hong Kong, namely, Tiu Chung Chau (T), Big Wave Bay (B), Beaufort Island (L) and Discovery Bay (D, Fig. 1). Over 100 limpets were randomly collected between 1.25 and $2.00 \mathrm{~m}$ above Chart Datum at each shore in each year. All specimens were fixed in 95\% ethanol and stored at $-20^{\circ} \mathrm{C}$ before laboratory analysis. In the laboratory, maximum shell length $( \pm 0.1 \mathrm{~mm})$ was measured, and population histograms (1 mm size interval) generated for each shore. Individual cohorts were separated using Bhattacharya's method (Bhattacharya 1967) using FiSAT (FAO-ICLARM Fish Stock Assessment Tool, Gayanilo and Pauly 1997) for each shore in each year. Two of the cohorts, namely, the new settlers of the year and the settlers from the previous year, were used for subsequent analysis, resulting in four identifiable cohorts $(1998,1999,2006$ and 2007) from each shore $\left(\Sigma_{\text {sample }}=4\right.$ cohorts $\times 4$ shores $=16$ samples). The total number of specimens used for the genetic study was 408 (Table 1).

DNA extraction and microsatellite amplification

Genomic DNA was extracted using the Qiagen QIAamp ${ }^{\circledR}$ DNA Mini Kit (Catalogue no. 51306) according to the 162

$\begin{array}{lll}\text { Journal : Large 227 } & \text { Dispatch : } \mathbf{1 2 - 1 0 - 2 0 0 9} & \text { Pages : } \mathbf{1 3} \\ \text { Article No. : } \mathbf{1 3 2 0} & \square \text { LE } & \square \text { TYPESET } \\ \text { MS Code : } \quad \text { MABI-D-09-00254 } & \sim_{\text {CP }} & \checkmark \text { DISK }\end{array}$


Fig. 1 Cellana grata. Sampling locations distributed across Hong Kong

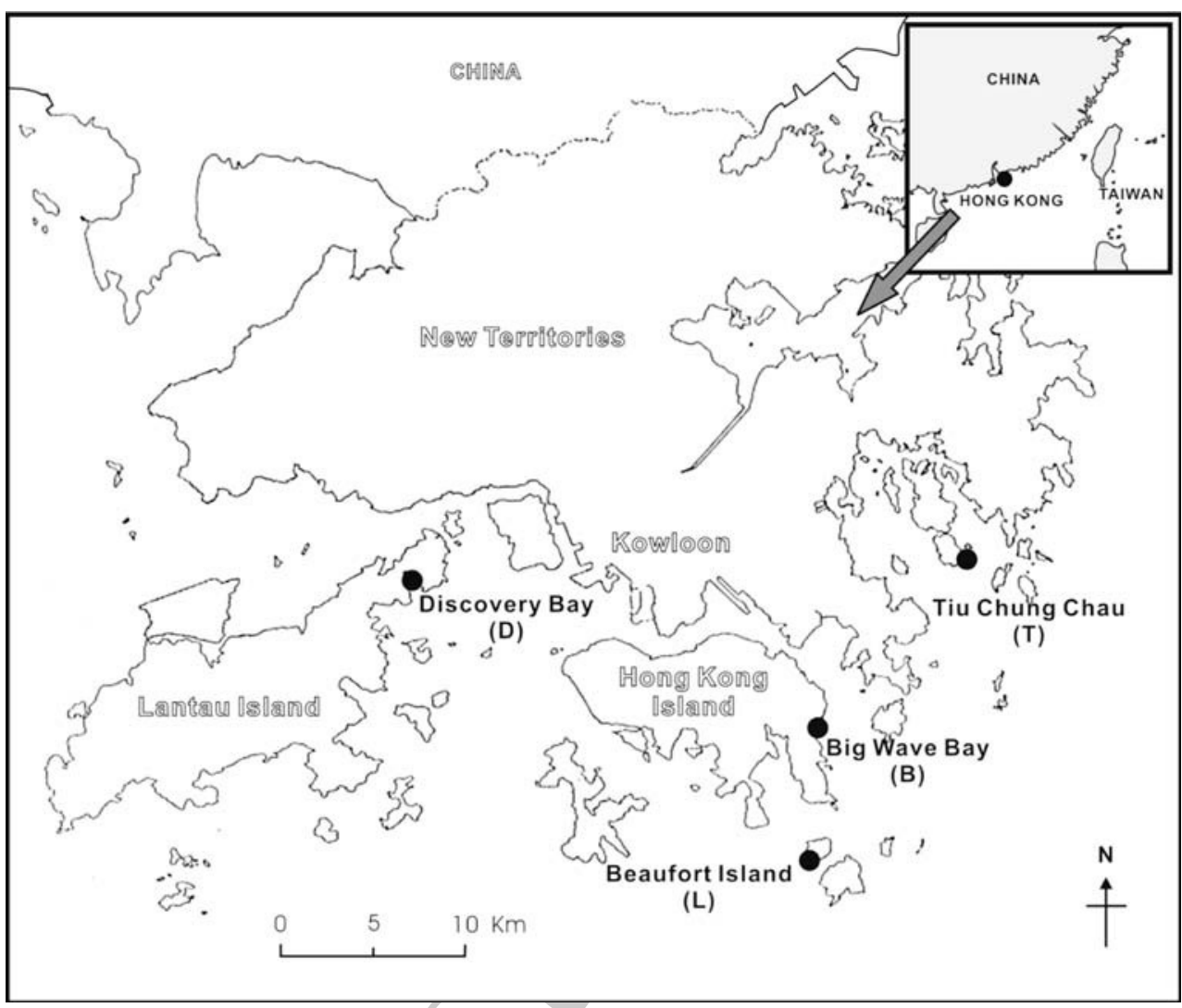

164

165

166

167

168

169

170

171

172

173

174

175

176

177

178

179

180

181

182

183

184

185

186

187

188 manufacturer's protocol. DNA was eluted with $60 \mu \mathrm{l}$ of Buffer TE and was kept at $-20^{\circ} \mathrm{C}$. Individuals were genotyped at five novel microsatellite loci developed (primer sequences, annealing temperatures and characters of the loci are detailed in $\mathrm{Ng}$ et al. 2009). Forward primers were fluorescently labeled. Polymerase chain reactions (PCR) were set up with $20 \mathrm{ng}$ of genomic DNA, 0.8 unit of Taq Polymerase (Qiagen), $1.25 \mathrm{mM} \mathrm{MgCl} 2,0.2 \mu \mathrm{M}$ of forward and reverse primers, and $0.2 \mu \mathrm{M}$ of each dNTPs in $20 \mu \mathrm{l}$ reaction mixes. Reaction profiles were set at for $15 \mathrm{~min}$ at $95^{\circ} \mathrm{C}, 39$ cycles of $1 \mathrm{~min}$ at $94^{\circ} \mathrm{C}, 50 \mathrm{~s}$ at appropriate annealing temperature, and $90 \mathrm{~s}$ at $72^{\circ} \mathrm{C}$, and a final extension for $5 \mathrm{~min}$ at $72^{\circ} \mathrm{C}$. Amplified products were run in a sequencing gel using an ABI 3100 automated sequencer with 400HD ROX ${ }^{\mathrm{TM}}$ (Applied Biosystems) as an internal size standard. Allele sizes were scored using GeneMarker (Softgenetics).

Population genetic analysis

For each sample, allelic richness was computed for each locus using FSTAT v.2.9.3.2 (Goudet 1995). Observed $\left(H_{\mathrm{O}}\right)$ and expected $\left(H_{\mathrm{E}}\right)$ heterozygosities were calculated using GENETIX v.4.05 (Belkhir et al. 2005). $F_{\text {IS }}$ were calculated according to Weir and Cockerham (1984). Deviation from the Hardy-Weinberg equilibrium was tested using GENEPOP v.3.4 (Raymond and Rousset 1995) using the Markov chain method (Guo and Thompson 1992). Genotypic linkage disequilibria between any two loci were tested using Markov chain and Fisher exact tests (10,000 dememorization, 1,000 batches, 5,000 iterations). The potential deviations from Hardy-Weinberg equilibrium due to the presence of null alleles were estimated using MICRO-CHECKER version 2.2.3 (van Oosterhaut et al. 2004).

As differences in genetic diversity among the samples were noted (see "Results"), evidence for recent changes in effective population size was tested. Populations that have experienced a recent reduction in their effective population size exhibit a correlative reduction in allele numbers and gene diversity (Hardy-Weinberg heterozygosity) at polymorphic loci. Allele numbers are, however, reduced faster then gene diversity, and hence observed gene diversity is higher than the expected equilibrium gene diversity in a recently bottlenecked population (Cornuet and Luikart 1996). To estimate this, heterozygosity values $\left(H_{\mathrm{e}}\right)$ for each sample were tested to investigate whether they exceeded those expected at mutation-drift equilibrium $\left(H_{\text {eq }}\right)$ under the infinite alleles modes (IAM), strict stepwise mutation model (SMM) and 2-phase model (TPM). Computation was performed using BOTTLENECK (Cornuet and Luikart 1996), with the proportion of single-step mutations set to $70 \%$ for TPM. The null hypothesis of no difference between $H_{\mathrm{e}}$ and $H_{\mathrm{eq}}$ was determined using the Wilcoxon
189

190

191

192

193

194

195

196

197

198

199

200

201

202

203

204

205

206

207

208

209

210

211

212

213

214

215

\begin{tabular}{|l|lll|}
\hline Journal : Large 227 & Dispatch : $\mathbf{1 2 - 1 0 - 2 0 0 9}$ & Pages : $\mathbf{1 3}$ \\
Article No. : $\mathbf{1 3 2 0}$ & $\square$ LE & $\square$ TYPESET \\
& MS Code : MABI-D-09-00254 & $\sim_{\text {CP }}$ & $\checkmark$ DISK \\
\hline
\end{tabular}


sign-rank test that provides higher power in the case of few microsatellite loci (Luikart and Cornuet 1998). The four shores for each cohort were also combined for overall estimates of potential bottlenecks in each cohort.

Genetic differentiation among samples was evaluated for the two temporal collections, i.e. 1998/1999 and 2007/ 2007, using $F$-statistics as implemented in GENETIX v.4.05. Global and pairwise $F_{\mathrm{ST}}$ were calculated across all the samples following Weir and Cockerham's $\theta$ (1984) and the $95 \%$ confidence intervals (C.I.) generated by 1,000 bootstrap iterations. Population differentiation was also tested by Fisher's exact tests using the Markov chain method (10,000 dememorization, 1,000 batches, 5,000 iterations) that takes into account low-frequency alleles and provides unbiased estimates of exact $P$ values. The test was conducted both globally and between sample pairs using GENEPOP v.3.4 with the null hypothesis that "allelic distribution is identical across populations". In all tests, significance levels were corrected for multiple comparisons using a sequential Bonferroni technique with overall $\alpha=0.05$ (Rice 1989).

Pairwise sample by sample genetic distances were calculated following Cavalli-Sforza and Edwards (1967) to generate chord distance $\left(D_{\mathrm{CE}}\right)$ using GENETIX v.4.05. This method makes no assumption of mutation, and distances are standardized with respect to random drift. Compared with other frequency-based genetic distances, $D_{\mathrm{CE}}$ offers lower sampling error and provides a more efficient mechanism to generate correct tree topologies under different demographic conditions (Takezaki and Nei 1996). The $D_{\mathrm{CE}}$ matrix was visualized using multidimensional scaling as implemented in PRIMER 6 (Clarke and Gorley 2006).

Partitioning of genetic variability into spatial and temporal components was performed using an analysis of molecular variance (AMOVA) in ARLEQUIN v.3.1 (Excoffier et al. 2005). For spatial analysis, genetic variability was partitioned into within shore $\left(\Phi_{\mathrm{SC}}\right)$ and between shores $\left(\Phi_{\mathrm{CT}}\right)$ variation. The variability components were evaluated separately for 1998/1999 and 2006/2007 collections. For temporal analysis, an AMOVA was carried out by grouping the samples by sampling time (i.e. 1998/1999 versus 2006/2007 collections) to examine whether there was significant variation in population structure over 10 years. Isolation by distance (IBD) between samples was evaluated for 1998/1999 and 2006/2007 collections using the Mantel test as implemented in GENETIX v.4.05 $\left(10,000\right.$ permutations) by correlating linearized $F_{\mathrm{ST}}$ (i.e. $\left.F_{\mathrm{ST}} /\left[1-F_{\mathrm{ST}}\right]\right)$ to the hydrographical distances, which were measured as the minimal along-shore distance between shores. To evaluate the effective population size, the moments-based method of Waples (1989) was employed, which estimates $N_{\mathrm{e}}$ from the standardized variance in allele frequency between temporal samples separated by a known number of generations. The generation time was set at 4 years based on population dynamics observation that revealed the general existence of cohorts from $0+$ to $3+$ years for the species (Huang 2001). Samples from $1998 / 1999$ collection were combined into one generation, and the same was applied for the 2006/2007 collection. Calculation was performed using NEESTIMATOR version 1.3 (Peel et al. 2004).

Assignment tests were conducted to estimate the probability of individuals that would be assigned to the stock origin based on genotypic data using the algorithm suggested by Cornuet et al. (1999). The probability of belonging to a group was computed for each individual, and individuals were assigned to one of the sixteen samples with the highest score using GENECLASS2 (Piry et al. 2004) under the Bayesian criteria (Rannala and Mountain 1997). A 10,000 test simulation was performed with resampling by the "leave-one-out" option that corrects for the bias of over rejection of resident individuals (Paetkau et al. 2004). The assignment rates among samples/collections were tested using ANOVA with arcsine square-root transformation.

\section{Results}

\section{Demographic structure}

Two to three distinct cohorts could be identified in all the 8 collections ( 4 shores $\times 2$ collection years), with high $(>2)$ separation indices. The mean total length of the newly settled cohort ranged from 8.7 to $12.7 \mathrm{~mm}$ and 18.1 to $26.0 \mathrm{~mm}$ for the second year cohort. A third cohort could be identified in Tiu Chung Chau (both in 1999 and 2007), Beaufort Island (1999 and 2007) and Discovery Bay (1999) with mean total length ranging from 25.9 to $35.3 \mathrm{~mm}$. The cohort size range shows good agreement to local age-size observations (Liu 1994b). To avoid mixing between cohorts, only specimens within an average cohort total length \pm 1 SD were selected for subsequent analysis (Table 1).

Genetic diversity

The five microsatellite loci showed high polymorphism across all the samples, with mean allelic richness $(R)$ ranging from 14.56 to 16.85 , with expected heterozygosity $\left(H_{\mathrm{E}}\right)$ from 0.884 to 0.922 and observed heterozygosity $\left(H_{\mathrm{O}}\right)$ from 0.846 to 0.901 (Table 1). Significant linkage disequilibrium was detected in only one out of 170 tests for individual samples and pair of loci (between loci C583 and C584 in sample L99, $P=0.022$ ), but the global test was not significant for all loci pairs across all samples.
307

308

309

310

311

312

313

314

315

$\begin{array}{lll}\text { Journal : Large 227 } & \text { Dispatch : } \mathbf{1 2 - 1 0 - 2 0 0 9} & \text { Pages : } \mathbf{1 3} \\ \text { Article No. : } \mathbf{1 3 2 0} & \square \text { LE } & \square \text { TYPESET } \\ \text { MS Code : } \quad \text { MABI-D-09-00254 } & \sim_{\text {CP }} & \checkmark \text { DISK }\end{array}$


Table 1 Cellana grata: allelic richness $(R)$, expected $\left(H_{\mathrm{E}}\right)$ and observed $\left(H_{\mathrm{O}}\right)$ heterozygosity, inbreeding coefficient $\left(F_{\mathrm{IS}}\right)$ for each sample and locus, and $F_{\text {IS }}$ for pooling of consecutive cohorts (Pooled $F_{\text {IS }}$ ) following David et al. (1997)

\begin{tabular}{|c|c|c|c|c|c|c|c|c|c|c|}
\hline \multirow[t]{2}{*}{ Shore } & \multirow[t]{2}{*}{ Cohort } & \multirow[t]{2}{*}{$N$} & \multirow[t]{2}{*}{ Sample code } & \multirow[t]{2}{*}{ Parameter } & \multicolumn{6}{|l|}{ Locus } \\
\hline & & & & & A8 & B97 & C186 & C583 & C584 & Multilocus \\
\hline \multirow[t]{18}{*}{ Tiu Chung Chau } & \multirow[t]{4}{*}{1998} & \multirow[t]{4}{*}{22} & \multirow[t]{4}{*}{ T98 } & $R$ & 17.06 & 13.15 & 13.29 & 13.74 & 11.15 & 13.68 \\
\hline & & & & $H_{\mathrm{E}}$ & 0.934 & 0.910 & 0.901 & 0.916 & 0.874 & 0.907 \\
\hline & & & & $H_{\mathrm{O}}$ & 0.864 & 0.909 & 0.773 & 0.900 & 1.000 & 0.889 \\
\hline & & & & $F_{\text {IS }}$ & +0.098 & +0.024 & +0.165 & $+0.043^{*}$ & -0.121 & $+0.043^{*}$ \\
\hline & \multirow[t]{5}{*}{1999} & \multirow[t]{5}{*}{20} & \multirow[t]{4}{*}{ T99 } & $R$ & 15.57 & 14.01 & 11.07 & 15.39 & 10.26 & 13.26 \\
\hline & & & & $H_{\mathrm{E}}$ & 0.918 & 0.895 & 0.889 & 0.923 & 0.880 & 0.901 \\
\hline & & & & $H_{\mathrm{O}}$ & 0.842 & 0.850 & 0.800 & 0.950 & 0.842 & 0.857 \\
\hline & & & & $F_{\text {IS }}$ & +0.110 & +0.076 & +0.125 & -0.004 & +0.069 & +0.075 \\
\hline & & & T98/T99 & Pooled $F_{\text {IS }}$ & & & & & & $+0.058 *$ \\
\hline & \multirow[t]{4}{*}{2006} & \multirow[t]{4}{*}{31} & \multirow[t]{4}{*}{ T06 } & $R$ & 15.27 & 11.88 & 14.93 & 15.84 & 10.60 & 13.70 \\
\hline & & & & $H_{\mathrm{E}}$ & 0.900 & 0.896 & 0.925 & 0.925 & 0.871 & 0.903 \\
\hline & & & & $H_{\mathrm{O}}$ & 0.800 & 0.800 & 0.850 & 0.950 & 0.950 & 0.870 \\
\hline & & & & $F_{\text {IS }}$ & +0.136 & +0.133 & $+0.107^{*}$ & -0.001 & -0.065 & +0.063 \\
\hline & \multirow[t]{5}{*}{2007} & \multirow[t]{5}{*}{30} & \multirow[t]{4}{*}{$\mathrm{T} 07$} & $R$ & 17.30 & 14.96 & 12.71 & 16.60 & 10.78 & 14.47 \\
\hline & & & & $H_{\mathrm{E}}$ & 0.940 & 0.925 & 0.904 & 0.934 & 0.853 & 0.911 \\
\hline & & & & $H_{\mathrm{O}}$ & 0.850 & 0.850 & 0.900 & 0.950 & 0.850 & 0.880 \\
\hline & & & & $F_{\text {IS }}$ & +0.121 & +0.107 & +0.030 & +0.007 & +0.029 & +0.059 \\
\hline & & & T06/T07 & Pooled $F_{\text {IS }}$ & & & & & & +0.060 \\
\hline \multirow[t]{18}{*}{ Big wave Bay } & 1998 & 20 & B98 & $R$ & 14.92 & 13.39 & 13.57 & 15.46 & 9.30 & 13.33 \\
\hline & & & & $H_{\mathrm{E}}$ & 0.911 & 0.914 & 0.913 & 0.928 & 0.873 & 0.908 \\
\hline & & & & $H_{\mathrm{O}}$ & 0.900 & 0.900 & 0.900 & 0.900 & 0.900 & 0.900 \\
\hline & & & & $F_{\text {IS }}$ & +0.038 & +0.041 & +0.039 & +0.055 & -0.006 & +0.034 \\
\hline & 1999 & 21 & B99 & $R$ & 17.82 & 14.02 & 13.58 & 15.41 & 11.52 & 14.47 \\
\hline & & & & $H_{\mathrm{E}}$ & 0.940 & 0.918 & 0.912 & 0.909 & 0.873 & 0.910 \\
\hline & & & & $H_{\mathrm{O}}$ & 0.952 & 0.905 & 0.905 & 0.905 & 0.905 & 0.914 \\
\hline & & & & $F_{\text {IS }}$ & +0.011 & +0.039 & +0.032 & +0.029 & -0.012 & +0.020 \\
\hline & & & B98/B99 & $\mathrm{P}_{0}$ & & & & & & +0.025 \\
\hline & 2006 & 28 & B06 & & 15.98 & 13.02 & 14.51 & 15.53 & 13.18 & 14.44 \\
\hline & & & & $H_{\mathrm{C}_{\mathrm{C}}}$ & 0.911 & 0.918 & 0.918 & 0.908 & 0.910 & 0.913 \\
\hline & & & & $H_{\mathrm{O}}$ & 0.900 & 0.850 & 0.950 & 0.950 & 1.00 & 0.930 \\
\hline & & & & $F_{\text {IS }}$ & +0.038 & +0.099 & -0.010 & -0.021 & -0.073 & +0.007 \\
\hline & 2007 & 32 & B0 & $R$ & 14.92 & 13.66 & 13.53 & 17.01 & 10.87 & 14.00 \\
\hline & & & & $H_{\mathrm{E}}$ & 0.924 & 0.920 & 0.901 & 0.930 & 0.880 & 0.911 \\
\hline & & & & $H_{\mathrm{O}}$ & 0.947 & 0.850 & 1.000 & 0.950 & 0.950 & 0.939 \\
\hline & & & & $F_{\text {IS }}$ & +0.051 & +0.102 & -0.084 & +0.004 & -0.054 & +0.005 \\
\hline & & & B06 & Pooled $F_{\text {IS }}$ & & & & & & +0.005 \\
\hline Beaufort Island & 1998 & 3 & L98 & $R$ & 14.94 & 14.29 & 14.02 & 14.43 & 11.71 & 13.88 \\
\hline & & & & $H_{\mathrm{E}}$ & 0.914 & 0.923 & 0.915 & 0.906 & 0.890 & 0.910 \\
\hline & & & & $H_{\mathrm{O}}$ & 0.850 & 0.850 & 0.850 & 0.800 & 0.800 & 0.830 \\
\hline & & & & $F_{\text {IS }}$ & +0.095 & +0.104 & +0.097 & +0.142 & $+0.126^{*}$ & $+0.113^{*}$ \\
\hline & 1999 & 18 & L99 & $R$ & 17.70 & 13.33 & 12.99 & 11.92 & 12.73 & 13.73 \\
\hline & & & & $H_{\mathrm{E}}$ & 0.920 & 0.898 & 0.914 & 0.888 & 0.897 & 0.903 \\
\hline & & & & $H_{\mathrm{O}}$ & 0.889 & 0.833 & 0.833 & 0.778 & 0.944 & 0.855 \\
\hline & & & & $F_{\text {IS }}$ & +0.062 & +0.101 & +0.116 & +0.150 & -0.025 & +0.081 \\
\hline & & & L98/L99 & Pooled $F_{\text {IS }}$ & & & & & & $+0.098 *$ \\
\hline
\end{tabular}

\begin{tabular}{|l|lll|}
\hline & Journal : Large 227 & Dispatch : $\mathbf{1 2 - 1 0 - 2 0 0 9}$ & Pages : $\mathbf{1 3}$ \\
Article No. : $\mathbf{1 3 2 0}$ & $\square$ LE & $\square$ TYPESET \\
& MS Code : MABI-D-09-00254 & $\checkmark$ CP & $\checkmark$ DISK \\
\hline
\end{tabular}


Table 1 continued

\begin{tabular}{|c|c|c|c|c|c|c|c|c|c|c|}
\hline \multirow[t]{2}{*}{ Shore } & \multirow[t]{2}{*}{ Cohort } & \multirow[t]{2}{*}{$N$} & \multirow[t]{2}{*}{ Sample code } & \multirow[t]{2}{*}{ Parameter } & \multicolumn{6}{|l|}{ Locus } \\
\hline & & & & & A8 & B97 & $\mathrm{C} 186$ & C583 & C584 & Multilocus \\
\hline & 2006 & 33 & L06 & $R$ & 15.41 & 11.66 & 16.55 & 16.70 & 14.02 & 14.87 \\
\hline & & & & $H_{\mathrm{E}}$ & 0.914 & 0.888 & 0.938 & 0.926 & 0.916 & 0.916 \\
\hline & & & & $H_{\mathrm{O}}$ & 0.850 & 0.850 & 0.900 & 0.950 & 1.00 & 0.910 \\
\hline & & & & $F_{\text {IS }}$ & +0.095 & +0.068 & +0.066 & +0.001 & -0.066 & +0.032 \\
\hline & 2007 & 32 & L07 & $R$ & 19.44 & 15.75 & 15.75 & 15.59 & 9.96 & 15.30 \\
\hline & & & & $H_{\mathrm{E}}$ & 0.948 & 0.928 & 0.928 & 0.914 & 0.868 & 0.917 \\
\hline & & & & $H_{\mathrm{O}}$ & 0.850 & 0.850 & 1.000 & 0.950 & 0.900 & 0.910 \\
\hline & & & & $F_{\text {IS }}$ & $+0.128 *$ & +0.109 & -0.053 & -0.014 & -0.012 & +0.033 \\
\hline & & & L06/L07 & Pooled $F_{\text {IS }}$ & & & & & & +0.033 \\
\hline \multirow[t]{21}{*}{ Discovery Bay } & 1998 & 20 & D98 & $R$ & 15.40 & 12.32 & 16.72 & 13.30 & 9.49 & 13.45 \\
\hline & & & & $H_{\mathrm{E}}$ & 0.935 & 0.900 & 0.930 & 0.888 & 0.873 & 0.905 \\
\hline & & & & $H_{\mathrm{O}}$ & 0.900 & 0.750 & 0.950 & 0.750 & 0.900 & 0.850 \\
\hline & & & & $F_{\text {IS }}$ & +0.105 & +0.191 & +0.004 & +0.180 & -0.006 & +0.095 \\
\hline & 1999 & 15 & D99 & $R$ & 16.39 & 13.66 & 13.00 & 18.25 & 10.73 & 14.41 \\
\hline & & & & $H_{\mathrm{E}}$ & 0.920 & 0.916 & 0.903 & 0.933 & 0.873 & 0.909 \\
\hline & & & & $H_{\mathrm{O}}$ & 0.867 & 0.867 & 0.929 & 0.867 & 0.867 & 0.879 \\
\hline & & & & $F_{\text {IS }}$ & +0.092 & +0.088 & +0.009 & +0.106 & +0.042 & +0.068 \\
\hline & & & D98/D99 & Pooled $F_{\text {IS }}$ & & & & & & +0.082 \\
\hline & 2006 & 31 & D06 & $R$ & 16.70 & 14.64 & 14.39 & 14.20 & 10.89 & 14.16 \\
\hline & & & & $H_{\mathrm{E}}$ & 0.903 & 0.914 & 0.910 & 0.911 & 0.889 & 0.905 \\
\hline & & & & $H_{\mathrm{O}}$ & 0.800 & 0.850 & 0.900 & 0.900 & 0.800 & 0.850 \\
\hline & & & & $F_{\text {IS }}$ & +0.139 & +0.095 & +0.037 & +0.038 & +0.125 & +0.087 \\
\hline & 2007 & 35 & D07 & $R$ & & 13.52 & 14.70 & 15.18 & 12.84 & 14.63 \\
\hline & & & & $H_{\mathrm{E}}$ & & 0.896 & 0.916 & 0.918 & 0.908 & 0.912 \\
\hline & & & & $H_{\mathrm{O}}$ & 0.800 & 0.950 & 0.950 & 0.900 & 0.900 & 0.900 \\
\hline & & & & $F_{\text {IS }}$ & +0.158 & -0.034 & -0.011 & +0.045 & +0.034 & +0.039 \\
\hline & & & D06/D07 & Pooled $F_{\text {IS }}$ & & & & & & $+0.061^{*}$ \\
\hline & & 408 & & & 16.71 & 14.23 & 14.25 & 15.41 & 11.42 & \\
\hline & & & & & 0.921 & 0.907 & 0.913 & 0.916 & 0.883 & \\
\hline & & & & Mean $H_{\mathrm{O}}$ & 0.859 & 0.857 & 0.899 & 0.897 & 0.907 & \\
\hline
\end{tabular}

Asterisks indicate deviation from Hardy-Weinberg equilibrium by exact test $\left({ }^{*} P<0.05\right)$

Deviation from the Hardy-Weinberg equilibrium was observed in only 4 out of 80 cases involving 4 loci $(P<0.05$; Table 1$)$, and all cases were due to heterozygote deficit with $F_{\text {IS }}$ ranging from 0.043 to 0.128 . Multilocus estimates of $F_{\text {IS }}$ were significant in 2 of the 16 samples (T98 and L98, $P<0.05$ ). MICRO-CHECKER results suggested the significant $F_{\text {IS }}$ in T98 was caused by the presence of null alleles in locus C583. Genotypes were adjusted for the sample following the Brookfield (1996) null allele estimator 1 method. The subsequent allele frequency-based analyses ( $F_{\mathrm{ST}}$, AMOVA and assignment test) did not, however, show any differences before and after the adjustment (data not shown), and so all analyses were performed using the unadjusted data set. For sample L98, MICRO-CHECKER did not reveal the presence of null alleles, suggesting that the deviations from the HardyWeinberg equilibrium may be caused by other biological factors. Values of $F_{\text {IS }}$ were positive in 60 out of 80 tests (Table 1), indicating a general heterozygote deficit in the samples. Negative $F_{\text {IS }}$ were recorded in 19 cases, which showed a bias toward the locus C584 (10 cases) and samples from 2006/2007 collection (13 cases), but none of the estimates was significant. Contrasting $F_{\text {IS }}$ were observed in some consecutive cohorts that may represent temporal heterogeneity, so samples were pooled from the consecutive cohorts for $F_{\text {IS }}$ computation following David et al. (1997). Significant deviation was evidenced in three of the eight pooled cohorts, namely, T98/T99, L98/L99 and D06/D07 (Table 1), suggesting the existence of localized temporal variation in some shores.

\begin{tabular}{|c|c|c|c|c|}
\hline & Journal : Large 227 & Dispatch : & 12-10-2009 & Pages: 13 \\
\hline & $\begin{array}{l}\text { Article No. : } 1320 \\
\text { MS Code : } \quad \text { MABI-D-09-00254 }\end{array}$ & $\begin{array}{l}\square \\
\boldsymbol{\sim}_{\mathrm{CP}}^{\mathrm{LE}} \\
\end{array}$ & & $\begin{array}{l}\square \text { TYPESET } \\
\Downarrow \text { DISK } \\
\end{array}$ \\
\hline
\end{tabular}


Table 2 Cellana grata: across-shore fixation index (overall $F_{\mathrm{ST}}$ ) and the associated significance $(P)$, inbreeding coefficient $\left(F_{\mathrm{IS}}\right)$ and the associated significance $(P)$, expected $\left(H_{\mathrm{E}}\right)$ and observed $\left(H_{\mathrm{O}}\right)$ heterozygosity, and allelic richness $(R)$ for each locus in the two temporal collections

\begin{tabular}{llllllll}
\hline Locus & Overall $F_{\mathrm{ST}}$ & $P$ & \multicolumn{1}{l}{$F_{\mathrm{IS}}$} & $P$ & $H_{\mathrm{E}}$ & $H_{\mathrm{O}}$ & $R$ \\
\hline 1998/1999 collection & & & & & & \\
A8 & 0.0028 & 0.1105 & 0.076 & 0.0413 & 0.924 & 0.883 & 16.23 \\
B97 & 0.0026 & 0.0885 & 0.081 & 0.1514 & 0.909 & 0.858 & 13.52 \\
C186 & 0.0021 & 0.1153 & 0.076 & 0.2176 & 0.910 & 0.868 & 13.53 \\
C583 & 0.0015 & 0.0493 & 0.085 & 0.0114 & 0.911 & 0.856 & 14.74 \\
C584 & 0.0024 & 0.2914 & 0.006 & 0.5799 & 0.879 & 0.895 & 10.86 \\
All & 0.0023 & 0.0145 & 0.065 & 0.0067 & & & \\
2006/2007 collection & & & & & & \\
A8 & 0.0008 & 0.2120 & 0.108 & 0.0126 & 0.920 & 0.850 & 16.49 \\
B97 & 0.0006 & 0.1151 & 0.085 & 0.1795 & 0.911 & 0.856 & 13.64 \\
C186 & 0.0008 & 0.5215 & 0.010 & 0.4750 & 0.918 & 0.931 & 14.63 \\
C583 & 0.0013 & 0.7210 & 0.007 & 0.8815 & 0.920 & 0.938 & 15.83 \\
C584 & 0.0004 & 0.2785 & -0.010 & 0.7820 & 0.887 & 0.919 & 11.64 \\
All & 0.0008 & 0.2891 & 0.041 & 0.1673 & & & \\
\hline
\end{tabular}

346

347

348

349

350

351

352

353

354

355

356

357

358

359

360

361

362

363

364

365

366

367

368

369

370

371

372

373

374

375

376
A multilocus significant deviation from the HardyWeinberg equilibrium was recorded for the 1998/1999 collection $\left(F_{\mathrm{IS}}=0.065\right.$, exact test: $\left.P=0.0067\right)$, reflecting overall heterozygote deficiency (Table 2). The exact test for the 2006/2007 collection was, however, not significant ( $F_{\text {IS }}=0.041$, exact test: $P=0.1673$ ). Three of the five microsatellite markers exhibited higher $F_{\text {IS }}$ in the 1998/ 1999 than 2006/2007 collection, in which only locus C583 showed a change in significance between the two collections. For individual loci, significant deviations were detected in locus A8 and C583 in the 1998/1999 collection and locus A8 only in the 2006/2007 collection (Table 2). Repeated analyses of the data with the exclusion of locus A8 or C583 did not reveal a difference in significance in both temporal collections (A8 excluded: 1998/1999, $P=0.0214 ; \quad 2006 / 2007, \quad P=0.6649 ; \quad$ C383 excluded: 1998/1999, $P=0.0406 ; 2006 / 2007, P=0.0927$ ).

Multilocus estimates of allelic richness were higher in the 2006/2007 than the 1998/1999 collection (Student's $t$-test: $P=0.034)$. As the change in allelic richness suggested a potential recent change in effective population size, evidence for a recent population bottleneck event was tested. Under the IAM, which is the least conservative model, a significant bottleneck $\left(H_{\mathrm{e}}>H_{\mathrm{eq}}: P<0.05\right)$ was detected in four samples (T98, B98, D99 and B07). These results, however, should be regarded with caution because of the poor correspondence of the IAM to microsatellite evolution (Weetman et al. 2006). Under the most conservative mutation model (SMM) and the more realistic mutation model (TPM) for microsatellites (Di Rienzo et al. 1994), no sign of a bottleneck was evidenced in all the sixteen samples. When the four spatial samples from each cohort were combined for overall analysis, only one significant result for the 1998 cohort under the IAM model was detected. Tests for the 1998 cohort under SMM and TPM models, as well as for the other three cohorts under all the three models, were not significant $(P>0.05)$.

Spatio-temporal genetic differentiation

Genetic differentiation in the two temporal collections was low, but variability in the 1998/1999 collection was higher, with non-overlapping C.I. $\quad\left(F_{\mathrm{ST}}=0.0023, \quad 95 \%\right.$ C.I. $=0.0014-0.0034)$ when compared with the 2006/ 2007 collection $\left(F_{\mathrm{ST}}=0.0008, \quad 95 \%\right.$ C.I. $=0.0002$ 0.0013 , Table 2). Of the five markers, only locus C583 $(P<0.0493)$ exhibited a significant $F_{\mathrm{ST}}$ value. Pairwise genetic differentiation between samples was detected in a few cases using both pairwise $F_{\mathrm{ST}}$ and exact tests (Table 3). Pairs showing significant differentiation did not exhibit apparent spatial or temporal patterns, but differentiation was generally more common within the 1998 cohort, and between 1998 and the other cohorts. No significant differentiation was observed in any pair within and between the 2006 and 2007 cohorts, suggesting a homogeneous structure among these cohorts.

Pairwise $D_{\mathrm{CE}}$ among the 16 samples revealed weak genetic structuring, but temporal or spatial samples were not well clustered (Fig. 2). Groupings were restricted to selected sample pairs, either from the same cohort of different shores (T99 and L99, B99 and D99) or from different cohorts of the same shore (B99 and B07, T06 and T98). The spatial AMOVA, however, showed a significant genetic structure among shores in the 1998/1999 collection $\left(\Phi_{\mathrm{CT}}=0.0031, P=0.048\right.$; Table 4$)$. In the $2006 / 2007$ collection, variation among shores was lower and not significant $\left(\Phi_{\mathrm{CT}}=0.0018, P=0.122\right)$. The variation among samples within shores was close to zero and not significant for both $1998 / 1999\left(\Phi_{\mathrm{SC}}=0.0005, P=0.703\right)$ and $2006 /$ $2007\left(\Phi_{\mathrm{SC}}=-0.0006, P=0.785\right)$ collections. The Mantel test exhibited no significant correlation between linearized $F_{\mathrm{ST}}$ and hydrographic distances in either 1998/1999 $(r=-0.109, \quad P>0.05) \quad$ or $2006 / 2007 \quad(r=0.246$, $P>0.05)$ collections. Partitioning of genetic variability between temporal collections revealed a non-significant structuring between the 1998/1999 and the 2006/2007 collections $\left(\Phi_{\mathrm{CT}}=0.0010, P=0.055\right.$; Table 5). As a higher differentiation was detected in the 1998/1999 collection, a further AMOVA was carried out for the partition between the 1998 and 1999 samples that revealed no significant differentiation $\left(\Phi_{\mathrm{CT}}=0.0007, \quad P=0.310\right)$ between the two cohorts.

The $N_{\mathrm{e}}$ estimates using Waples (1989) method for all temporal samples combined revealed a median of 599
384

385

386

387

388

389

390

391

392

393

394

395

396

397

398

399

400

401

402

403

404

405

406

407

408

409

410

411

412

413

414

415

416

417

418

419

420

421

422

423

424

425

426

427 
Table 3 Cellana grata: pairwise $F_{\mathrm{ST}}$ (Weir and Cockerham's $\theta$ ) (above diagonal) and exact tests of genetic differentiation (below diagonal) across the 16 samples

\begin{tabular}{|c|c|c|c|c|c|c|c|c|c|c|c|c|c|c|c|c|}
\hline Sample & T98 & B98 & 98 & D98 & T99 & B99 & L99 & D99 & T06 & B06 & L06 & D06 & T07 & B07 & L07 & D07 \\
\hline 98 & - & 0045 & 0061 & 0.0018 & 0.0025 & .0035 & $0103^{*}$ & 0.0003 & 0.005 & 08 & 0.0027 & 0.0050 & 0.0044 & $0.0134 *$ & 0.0063 & 0.0063 \\
\hline B98 & 0.1171 & & 0.0043 & 0.0026 & 0.0055 & -0.0018 & 0.0007 & -0.007 & 0.0043 & 0.0034 & 0.0003 & 0.0004 & 0.0016 & 0.0031 & -0.0022 & -0.0006 \\
\hline 98 & 0.0456 & 0.0397 & & $0.0097 *$ & 0.0041 & 0.0041 & 0.0013 & -0.0039 & 0.0018 & 0.0048 & 0.0028 & 0.0037 & 0.0020 & 0.0028 & 0.0083 & 0.0044 \\
\hline 98 & 0.3926 & 0.2394 & 0.0076 & & 0.0095 & 0.0043 & 0.0082 & -0.0034 & -0.0002 & $0.0123^{*}$ & 0.0035 & -0.002 & 0.0053 & 0.0060 & 0.0053 & 0.0025 \\
\hline Т99 & 0.3438 & 0.0403 & 0.0262 & 0.0112 & & 0.0064 & -0.0044 & -0.0043 & 0.0069 & 0.0043 & -0.0014 & -0.0015 & -0.005 & 0.0075 & 0.0070 & 0.0062 \\
\hline 399 & 0.3685 & 966 & .0792 & 4 & 0.1042 & & 0.006 & -0.0094 & 6 & 0.0074 & $2 *$ & 0.0040 & 0.00 & 3 & 3 & 037 \\
\hline L99 & 0.0192 & 0.3274 & 0.1387 & 0.0257 & 0.7137 & 0.1053 & & -0.0053 & 0.0029 & 0.0035 & -0.0075 & 0.0009 & -0.0016 & 0.007 & 0.0027 & -0.0002 \\
\hline D99 & 0.5122 & 0.8470 & 0.5064 & 0.7153 & 0.6349 & 0.9708 & 0.7233 & & -0.0041 & 0.0042 & -0.0002 & -0.0034 & -0.0030 & -0.0026 & & -0.0020 \\
\hline 06 & 0.2107 & 0.7274 & .0898 & o & 7 & 9 & 0 & 0.6232 & & 0.0006 & -0.0013 & -0.0046 & -0.0001 & 0.0017 & 0.0004 & 0.0002 \\
\hline 306 & 0.0612 & 0.2440 & 0.0280 & .0056 & 0.1929 & 0.1658 & 0.1739 & 0.1874 & 0.5831 & & 0.0008 & 0.0057 & 0.0004 & -0.0009 & -0.0002 & 0.0078 \\
\hline L06 & 0.3401 & 0.3091 & 0.2432 & 0.0898 & 0.4914 & 0.0344 & 0.9533 & 0.4550 & 0.5088 & 0.3747 & & 0.001 & -0.00 & 0.0055 & 0.0008 & -0.0042 \\
\hline 00 & 0.0535 & 0.3153 & 0.0900 & - & & 0.1090 & & & & & 0.4460 & & 0.0023 & 0.0068 & 0.0033 & -0.0019 \\
\hline Т07 & 0.3347 & 0.4563 & 405 & 126 & 0.8985 & 0.5352 & 0.5921 & 0.7890 & 0.5037 & 0.5196 & 0.7249 & 0.5837 & & 0.0002 & -0.0070 & -0.0006 \\
\hline B07 & 0.0012 & 0.1367 & 0.0573 & 0.1061 & 0.0448 & 0.6445 & 0.0312 & 0.5424 & 0.1687 & 0.6210 & 0.0568 & - & 0.3036 & & -0.0010 & 0.0079 \\
\hline 201 & 0.1051 & 0.7699 & 0.0074 & 0.0688 & 0.1618 & 0.5481 & 0.1251 & 0.9541 & 0.5147 & 0.7585 & 0.6239 & 0.2776 & 0.9638 & 0.2265 & & 0.0052 \\
\hline D07 & 0.1564 & 0.5011 & 0.0346 & 0.1240 & 0.0522 & 0.3638 & 0.3819 & 0.6909 & 0.4946 & 0.0833 & 0.8 & 0.662 & 0.8455 & 0.0563 & 0.1955 & - \\
\hline
\end{tabular}

Significance of $\theta$ was tested with 10,000 permutations $(* P<0.05)$. Exact tests with $P$ values $<0.05$ were indicated in bold, all values were not significant after sequential Bonferroni correction. Sample codes as in Table 3

428 with $95 \%$ confidence limits (CL) of 352-11,397. 429 Assignment tests revealed a mean value of only $8 \%$ 430 (ranged from 0 to $23.8 \%$ ) of individuals that was correctly 431 assigned to their original samples (Table 5). The propor432 tion of assignment to the same shores was $28.3 \%$ (10.6$43347.7 \%$ ), and for assignment to the same cohorts was $43433.6 \%(14.3-52.6 \%)$. The 1998/1999 collections showed a 435 higher rate of correct assignment to the original sample 436 (ANOVA, $P=0.018$ ) and the rate of assignment to the 437 same shore $(P=0.043)$ than the $2006 / 2007$ collection. In 438 contrast, the rates for assignment to the same cohort $439(P=0.794)$ and wrong assignment $(P=0.581)$ were not 440 significant.

\section{Discussion}

442 Analysis of temporal samples of Cellana grata over a 44310 year period reveals minor, patchy genetic structure 444 without clear spatial or temporal patterns. The major 445 observation is the contrasting genetic variability between 446 collections separated by 10 years (as indicated by the sig447 nificant heterozygote deficiency from Hardy-Weinberg 448 equilibrium, the higher global $F_{\mathrm{ST}}$ and significant spatial 449 AMOVA in the 1998/1999 but not in the 2006/2007 col450 lection). The genetic partitioning between the two temporal 451 collections was, however, weak. Such genetic heteroge452 neity over such small geographic and temporal scales is 453 generally believed to result from temporal variation in the 454 genetic composition of recruits (Johnson and Black 1982; 455 Li and Hedgecock 1998; Selkoe et al. 2006).

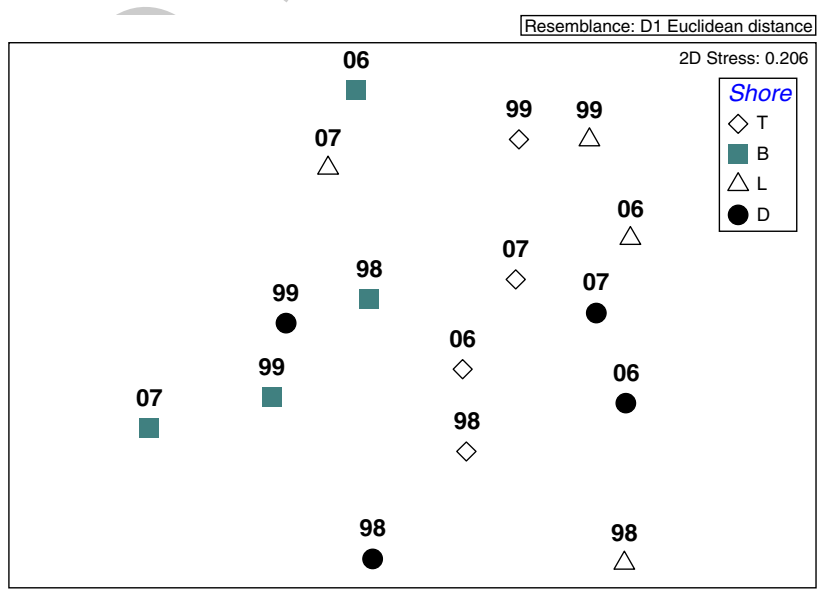

Fig. 2 Cellana grata. nMDS of pairwise sample by sample CavalliSforza and Edwards chord distance

Heterozygote deficiency

Heterozygote deficiencies relative to Hardy-Weinberg expectations (positive $F_{\text {IS }}$ ) were estimated for selected loci and overall for the 1998/1999 collection. Such deficiency is not uncommon among Patellogastropods (Corte-Real et al. 1996; Weber and Hawkins 2006; de Aranzamendi et al. 2008). The observed heterozygote deficiencies may be due to the presence of null alleles or biological processes such as inbreeding and Wahlund effects. In this study, it is unlikely for the null or non-amplifying allele to cause the observed heterozygote deficiencies as the level of $F_{\text {IS }}$ changed between the temporal collections for the same loci. This is especially true as it is using the corrected allele

\begin{tabular}{|l|ll|} 
Journal : Large 227 & Dispatch : 12-10-2009 & Pages : $\mathbf{1 3}$ \\
Article No. : $\mathbf{1 3 2 0}$ & $\square$ LE & $\square$ TYPESET \\
MS Code : MABI-D-09-00254 & $\sim_{\mathrm{CP}}$ & $\boldsymbol{\sim}$ DISK \\
\hline
\end{tabular}


Table 4 Cellana grata: AMOVA for spatial population genetic structure in 1998/1999 and 2006/2007 collections, and temporal population structure between the two collections

\begin{tabular}{|c|c|c|c|c|c|c|}
\hline Source of variation & $d f$ & $\begin{array}{l}\text { Sum of } \\
\text { squares }\end{array}$ & $\begin{array}{l}\text { Variance } \\
\text { components }\end{array}$ & $\begin{array}{l}\text { Percentage of } \\
\text { variation }\end{array}$ & Fixation indices & $P$ \\
\hline \multicolumn{7}{|l|}{ Four shores in $1998 / 1999$} \\
\hline Among shores & 3 & 8.79 & $0.00727 \mathrm{Va}$ & 0.31 & $\Phi_{\mathrm{CT}}=0.0031$ & 0.048 \\
\hline Among samples within shores & 4 & 9.46 & $0.00106 \mathrm{Vb}$ & 0.05 & $\Phi_{\mathrm{SC}}=0.0005$ & 0.703 \\
\hline Within samples & 304 & 702.32 & $2.32556 \mathrm{Vc}$ & 99.64 & $\Phi_{\mathrm{ST}}=0.0036$ & 0.223 \\
\hline \multicolumn{7}{|l|}{ Four shores in $2006 / 2007$} \\
\hline Among shores & 3 & 7.834 & $0.00413 \mathrm{Va}$ & 0.18 & $\Phi_{\mathrm{CT}}=0.0018$ & 0.122 \\
\hline Among samples within shores & 4 & 9.125 & $-0.00137 \mathrm{Vb}$ & -0.06 & $\Phi_{\mathrm{SC}}=-0.0006$ & 0.785 \\
\hline Within samples & 496 & 728.825 & $2.33598 \mathrm{Vc}$ & 99.88 & $\Phi_{\mathrm{ST}}=0.0012$ & 0.538 \\
\hline \multicolumn{7}{|l|}{$1998 / 1999$ versus $2006 / 2007$} \\
\hline Among the temporal collections & 1 & 3.245 & $0.00231 \mathrm{Va}$ & 0.10 & $\Phi_{\mathrm{CT}}=0.0010$ & 0.055 \\
\hline Among samples within collections & 14 & 35.209 & $0.00468 \mathrm{Vb}$ & 0.20 & $\Phi_{\mathrm{SC}}=0.0020$ & 0.301 \\
\hline Within samples & 815 & $1,413.143$ & $2.33086 \mathrm{Vc}$ & 99.70 & $\Phi_{\mathrm{ST}}=0.0029$ & 0.161 \\
\hline
\end{tabular}

Table 5 Cellana grata: assignment tests to determine the likelihood of an individual being classified in their original population by their genotypes conducted using GENECLASS2

\begin{tabular}{|c|c|c|c|c|c|c|c|c|}
\hline \multirow[t]{2}{*}{ Sample } & \multicolumn{2}{|c|}{ Assigned to correct shore and cohort } & \multicolumn{2}{|c|}{ Assigned to same shore } & \multicolumn{2}{|c|}{ Assigned to same cohort } & \multicolumn{2}{|c|}{ Assigned to wrong shores and cohorts } \\
\hline & $\%$ & 95\% C.I. & $\%$ & 95\% C.I. & $\%$ & 95\% C.I. & $\%$ & 95\% C.I. \\
\hline T98 & 4.8 & \multirow[t]{4}{*}{$13.6 \pm 16.3$} & 38.1 & \multirow[t]{4}{*}{$41.3 \pm 12.5$} & 28.6 & \multirow[t]{4}{*}{$28.4 \pm 18.2$} & 38.1 & \multirow[t]{4}{*}{$44.0 \pm 7.1$} \\
\hline B98 & 21.1 & & 31.6 & & 42.2 & & 47.4 & \\
\hline L98 & 23.8 & & 47.6 & & 28.6 & & 47.6 & \\
\hline D98 & 4.8 & & 47.7 & & 14.3 & & 42.9 & \\
\hline T99 & 11.1 & \multirow[t]{4}{*}{$9.7 \pm 3.0$} & 33.3 & \pm 12 & 44.4 & \multirow[t]{4}{*}{$37.1 \pm 12.6$} & 33.3 & \multirow[t]{4}{*}{$45.8 \pm 16.2$} \\
\hline B99 & 9.5 & & 19.0 & & 33.3 & & 57.1 & \\
\hline L99 & 11.1 & & 33.3 & & 27.8 & & 50.0 & \\
\hline D99 & 7.1 & & 21.4 & & 42.8 & & 42.9 & \\
\hline T06 & 0.0 & \multirow[t]{4}{*}{$2.6 \pm 4.8$} & 21.1 & \pm 8.0 & 21.1 & \multirow[t]{4}{*}{$33.4 \pm 14.2$} & 57.9 & \multirow[t]{4}{*}{$51.3 \pm 7.9$} \\
\hline B06 & 0.0 & & 19.0 & & 33.3 & & 47.6 & \\
\hline L06 & 5.3 & & 21.1 & & 36.9 & & 47.4 & \\
\hline D06 & 5.3 & & 10.6 & & 42.1 & & 52.6 & \\
\hline T07 & 0.0 & \multirow[t]{5}{*}{$6.2 \pm 7.7$} & 21.1 & \multirow[t]{5}{*}{$27.2 \pm 21.8$} & 52.6 & \multirow[t]{5}{*}{$34.5 \pm 25.16$} & 26.3 & \multirow[t]{5}{*}{$43.5 \pm 19.7$} \\
\hline B07 & 4.8 & & 47.7 & & 14.3 & & 42.9 & \\
\hline L07 & 10.5 & & 21.0 & & 36.8 & & 52.6 & \\
\hline D07 & 9.5 & & 19.0 & & 38.1 & & 52.4 & \\
\hline Total & $8.0 \pm 3.6$ & & 28.3 & & 33.6 & & $46.3 \pm 4.5$ & \\
\hline
\end{tabular}

469 frequency as suggested by MICRO-CHECKER for locus 470 C583 revealed no change in the significance of the Hardy471 Weinberg equilibrium, $F_{\mathrm{ST}}$ or AMOVA. Inbreeding or 472 localized recruitment due to the restricted dispersal of 473 gametes or larvae has been hypothesized to cause hetero474 zygote deficiencies (Magalon et al. 2005; Costantini et al. 475 2007). Such phenomenon is, however, more common in 476 species with low dispersal ability (Ben-Shlomo et al. 477 2001). Cellana limpets are broadcast spawners with a high dispersal potential (Bird et al. 2007). The dispersal ability of this species is also supported in this study, at least over the sampling range, by the panmictic structure among spatial samples in the 2006/2007 collection. In addition, heterozygote deficiencies were not congruent among loci in the data, indicating inbreeding is unlikely.

The Wahlund effect, reduction in heterozygosity resulting from sampling across subdivided populations, has been suggested in different taxa for cases of elevated $F_{\text {IS }}$ (David

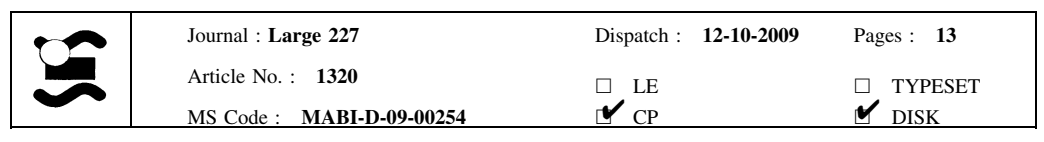


et al. 1997; Raymond et al. 1997). Johnson and Black (1984b) reported a patchy genetic structure with general deficit of heterozygotes in Siphonaria limpet species from the Australian coast and proposed that the deficiency was caused by mixing of larvae from different sources over a small geographic scale. On the other hand, mixing of subdivided populations could happen temporally, such as surges of larval within and between spawning events may be contributed from genetically distinct populations (Lenfant and Planes 2002; Maes et al. 2006). In this study, the observed heterozygosity reflected the potential Wahlund effect in the collections. A characteristic evolution of the deficit of heterozygotes under a temporal Wahlund effect is an increase in heterozygote deficiency in relation to the increasing number of cohorts pooled together (David et al. 1997). Some of the samples showed significant heterozygote deficiency when pooling consecutive cohorts, particularly for sample D06 and D07 that did not deviate before pooling, suggesting a potential temporal Wahlund effect. However, the low heterogeneity among the samples did not support the presence of genetically distinct source populations. This less profound structuring may be the result of recruitment variation at a localized scale in which different portions of the source population are recruited to each site depending on the localized oceanographic or environmental conditions at that time. Additionally, such uneven genetic distribution is likely to vary from year to year and lead to the contrasting genetic structure observed between the temporal collections in this study.

\section{Spatio-temporal genetic differentiation}

There was a higher degree of genetic differentiation in the $1998 / 1999$ collection when compared to the 2006/2007 collection. The spatial AMOVA indicated that this partitioning was contributed mainly by the variation among shores; assignment tests also revealed higher assignment rate to shores in the 1998/1999 collection. The lack of IBD, however, suggests that the distance between shores is not the determining factor for this variability. Such unpatterned spatial differentiation may reflect a random and uneven genetic composition among the shores. In other studies with comparable geographic ranges, spatial genetic structure of intertidal nudibranchs has been related to the scale of larval dispersal of specific years (Lambert et al. 2003), while Pedersen et al. (2000) also identified genetic heterogeneity within and between cohorts of mussel settlers. Both these studies regarded these patterns to be a result of large variation in recruit composition among cohorts. In the marine environment, reproductive success of free spawning adults is largely influenced by the variable oceanic conditions (Underwood and Fairweather 1989; Gaines and Bertness 1992) that may operate at various scales at different stages of the spawning process, affecting fertilization dynamics (Hodgson et al. 2007), larval dispersal and/or retention (Ayata et al. 2009) and survivorship (Botsford et al. 1994). The survivorship of progeny is unpredictable, and successful recruits may be contributed by only a small portion of the adult population in each spawning event. The extent of how many and which individuals are successful, therefore, may be largely determined by chance. Li and Hedgecock (1998) hypothesized that genetic heterogeneity among cohorts should be detectable if only a small proportion of adults are contributing to the recruits. It is noteworthy that significant pairwise genetic differentiation was more common within the 1998 cohort and between 1998 and the other cohorts. High fluctuation in recruitment over cohorts/spawning events has been proposed to boost genetic drift, decrease effective population size and cause temporal genetic structuring (Lenfant and Planes 2002; Maes et al. 2006). The differentiation between the 1998/ 1999 and the more homogeneous 2006/2007 collection was, however, non-significant (although $P=0.055$ ). Firstly, these observations imply a generally consistent larval supply over time and secondly that genetic drift caused by the spatial differentiation was not high enough to generate a substantial temporal structure.

It is surprising that the estimates of effective population size were not high over the study period, although the confidence limits were wide, and so this conclusion should be viewed with caution. Similar estimates were observed for oysters from Chesapeake Bay (Rose et al. 2006), and the low ratio of $N_{\mathrm{e}}$ to the population size was attributed to high variation in reproductive success. Lee and Boulding (2007) showed that genetic structure of Littorina keenae in the northeastern Pacific was temporally stable in general $\left(N_{\mathrm{e}} \approx 30,000\right)$, but low $N_{\mathrm{e}}(135)$ at selected sites reflected a 'sweepstake recruitment'. A review of effective to actual population size $\left(N_{\mathrm{e}} / N\right)$ over 102 taxa suggested an average of only $0.10-0.11$ of the population contributes progeny (Frankham 1995), while Turner et al. (2002) found that the $N_{\mathrm{e}}$ was five to three orders below the adult census size. The actual population sizes were not measured for each shore in this study. An abundance survey along various shores spanning the Hong Kong coastline in 1998-1999 revealed an average of 9.01 Cellana grata $\mathrm{m}^{-2}(\mathrm{SD}=44.06$, $n=45$ ). Assuming even population density over the survey area ( $3 \mathrm{~m}$ wide $\times 300 \mathrm{~m}$ along coastline $\times 4$ shores), the range of $N_{\mathrm{e}} / N$ estimates would be (352 to 11,397)/ $(9.01 \times 3 \times 300 \times 4)=0.011-0.351$. Such values should, however, be interpreted with care due to the involvement of uncertain parameters such as the juvenile/ adult proportion, sex ratio. The order of the estimates, however, does indicate the potentially small portion of effective spawners in the population, and hence potential susceptibility to recruitment variation. 
The arguments for recruitment variation generally highlight the importance of pre-settlement factors governing the resultant genetic differentiation (Hedgecock 1994; Flowers et al. 2002), although microenvironmental postsettlement selection has also been proposed (Johannesson et al. 1995). Cellana grata suffers from regular on-shore mass mortality during summer, due to heat and desiccation stress, where up to $80 \%$ of the population can be killed (Williams and Morritt 1995; Ngan 2006). A vast reduction in the effective population size may lead to a population bottleneck and results in reduction in allele number and gene diversity (Cornuet and Luikart 1996). Despite this potential, analyses did not reveal strong proof of a bottleneck under the more conservative and realistic SMM and TPM models (Di Rienzo et al. 1994). The lack of detection of a bottleneck implies the actual spawning population is either not affected or maintained at a relatively constant level by the summer mass mortality.

Although Cellana grata populations showed some degree of fine scale recruitment variation, the resulting genetic drift is probably not robust enough to have a strong impact on their overall genetic structure. Significant differentiation would be expected if the recruitment variation acted at a persistent and larger scale, but this was only found within the 1998/1999 samples and was not recorded in the 2006/2007 collection or between the two temporal collections. This agrees with the findings of Selkoe et al. (2006) who performed extensive analysis to reveal the combined effect of family structure (existence of siblings) and changes in larval delivery on the fine scale genetic structure in cohorts of kelp bass populations. As in the present study, Selkoe et al. (2006) concluded that the degree of genetic drift was not strong enough to impact the adult genetic structure. The potential driving forces affecting genetic population structure of limpets in this study are unlikely to operate in a consistent pattern over time, and any genetic variance was probably counteracted by gene flow among the shores. While the degree of the detected genetic differentiation only amounts to slight differences in allele frequencies that may not generate substantial biological effects (Waples 1998; Hedrick 1999), the results suggest the phenomenon of potential fine scale structuring due to recruitment variation under a scenario of broad scale genetic homogeneity. This work therefore highlights the interacting effects between recruitment dynamics and population connectivity in determining intertidal population genetic structure.

Acknowledgments We thank M. N. Chan for microsatellite characterization, R.I. Lewis for his input during the early parts of this study and Neil Hutchinson for analysis of population structure. We are especially grateful to Michael Hellberg for constructive, critical comment on the MS. This research was supported by the Research Grants Council, Hong Kong (Project no. HKU7238/97M).

\section{References}

Ayata SD, Ellien C, Dumas F, Dubois S, Thiebaut E (2009) Modelling larval dispersal and settlement of the reef-building polychaete Sabellaria alveolata: role of hydroclimatic processes on the sustainability of biogenic reefs. Cont Shelf Res 29:16051623

Belkhir K, Borsa P, Chikhi L, Faufaste N, Bonhomme F (2005) GENETIX v 4.05, logiciel sous Windows pour la génétique des populations. Laboratoire Génome et Populations. CNRS UPR 9060, Université Montpellier II

Ben-Shlomo R, Douek J, Rinkevish B (2001) Heterozygote deficiency and chimerism in remote populations of a colonial ascidian from New Zealand. Mar Ecol Prog Ser 209:109-117

Bernal-Ramírez JH, Adcock GJ, Hauser L, Carvalho GR, Smith PJ (2003) Temporal stability of genetic population structure in the New Zealand snapper, Pagrus auratus, and relationship to coastal currents. Mar Biol 142:567-574

Bhattacharya CG (1967) A simple method of resolution of a distribution into Gaussian components. Biometrics 23:115-135

Bird CE, Holland BS, Bowen BW, Toonen RJ (2007) Contrasting phylogeography in three endemic Hawaiian limpets (Cellana spp.) with similar life histories. Mol Ecol 16:3173-3186

Botsford LW, Moloney CL, Hastings A, Largier JL, Powell TM, Higgins K, Quinn JF (1994) The influence of spatially and temporally varying oceanographic conditions on meroplanktonic metapopulations. Deep-sea Res Pt II 41:107-145

Brookfield JFY (1996) A simple new method for estimating null allele frequency from heterozygote deficiency. Mol Ecol 5:453-455

Cavalli-Sforza LL, Edwards AWF (1967) Phylogenetic analysis: models and estimation procedures. Evolution 21:550-570

Chan BKK, Williams GA (2004) Population dynamics of the acorn barnacles, Tetraclita squamosa and Tetraclita japonica (Cirripedia: Balanomorpha), in Hong Kong. Mar Biol 146:149-160

Clarke KR, Gorley RN (2006) PRIMER v6: user manual/tutorial. PRIMER-E, Plymouth

Cornuet JM, Luikart G (1996) Description and power analysis of two tests for detecting recent population bottlenecks from allele frequency data. Genetics 144:2001-2014

Cornuet JM, Piry S, Luikart G, Estoup A, Solignac M (1999) New methods employing multilocus genotypes to select or exclude populations as origins of individuals. Genetics 153:1989-2000

Corte-Real H, Hawkins S, Thorpe J (1996) Population differentiation and taxonomic status of the exploited limpet Patella candei in the Macaronesian islands (Azores, Madeira, Canaries). Mar Biol 125:141-152

Costantini F, Fauvelot C, Abbiati M (2007) Fine-scale genetic structuring in Corallium rubrum: evidence of inbreeding and limited effective larval dispersal. Mar Ecol Prog Ser 340:109-119

David P, Perdieu MA, Pernot AF, Jarne P (1997) Fine-grained spatial and temporal population genetic structure in the marine bivalve Spisula ovalis. Evolution 51:1318-1322

De Aranzamendi MC, Sahade R, Tatian M, Chiappero MB (2008) Genetic differentiation between morphotypes in the Antarctic limpet Nacella concinna as revealed by inter-simple sequence repeat markers. Mar Biol 154:875-885

Di Rienzo A, Peterson AC, Garcza JC, Baldes AM, Slakin M, Freimer NB (1994) Mutational processes of simple-sequence repeat loci in human populations. Proc Natl Acad Sci USA 91:3166-3170

Excoffier L, Laval C, Schneider S (2005) Arlequin ver. 3.0: an integrated software package for population genetics data analysis. Evol Bioinform Online 1:47-50

Flowers JM, Schroeter SC, Burton RS (2002) The recruitment sweepstakes has many winners: genetic evidence from the sea urchin Strongylocentrotus purpuratus. Evolution 56:1445-1453 
Frankham R (1995) Effective population size/adult population size ratios in wildlife: a review. Genet Res 66:95-107

Gaines SD, Bertness MD (1992) Dispersal of juveniles and variable recruitment in sessile marine species. Nature 360:579-580

Gayanilo FCJ, Pauly D (1997) FAO/ICLARM stock assessment tools (FiSAT). Reference manual. FAO computer information series fisheries $8,262 \mathrm{pp}$

Goudet J (1995) FSTAT (version 1.2): a computer program to calculate $F$-statistics. J Hered 86:485-486

Guo SW, Thompson EA (1992) Performing the exact test for HardyWeinberg proportions for multiple alleles. Biometrics 48:361372

Hawkins SJ, Hartnoll RG (1982) Settlement patterns of Semibalanus balanoides (L.) in the Isle of Man (1977-1981). J Exp Mar Biol Ecol 62:271-283

Hedgecock D (1994) Does variance in reproductive success limit effective population sizes of marine organisms? In: Beaumont AR (ed) Genetics and evolution of aquatic organisms. Chapman \& Hall, London, pp 122-134

Hedrick PW (1999) Perspective: highly variable loci and their interpretation in evolution and conservation. Evolution 53:313318

Hepburn RI, Sale PF, Dixon B, Heath DD (2009) Genetic structure of juvenile cohorts of bicolor damselfish (Stegastes partitus) along the Mesoamerican barrier reef: chaos through time. Coral Reefs 28:277-288

Hodgson AN, Le Quesne WJF, Hawkins SJ, Bishop JDD (2007) Factors affecting fertilization success in two species of patellid limpet (Mollusca: Gastropoda) and development of fertilization kinetics models. Mar Biol 150:415-426

Huang R (2001) Spatial variation in Cellana grata populations: the interplay of population dynamics and food availability. $\mathrm{PhD}$ thesis, The University of Hong Kong, Hong Kong

Jenkins GP, Black KP, Wheatley MJ, Hatton DN (1997) Temporal and spatial variability in recruitment of a temperate, seagrassassociated fish is largely determined by physical processes in the pre- and post-settlement phases. Mar Ecol Prog Ser 148:2335

Johannesson K, Johannesson B, Lundgren U (1995) Strong natural selection causes microscale allozyme variation in a marine snail. Proc Natl Acad Sci USA 92:2602-2606

Johnson MS, Black R (1982) Chaotic genetic patchiness in an intertidal limpet, Siphonaria sp. Mar Biol 70:157-164

Johnson MS, Black R (1984a) Pattern beneath the chaos: the effect of recruitment on genetic patchiness in an intertidal limpet. Evolution 38:1371-1383

Johnson MS, Black R (1984b) The Wahlund effect and the geographical scale of variation in the intertidal limpet Siphonaria sp. Mar Biol 79:295-302

Kordos LM, Burton RS (1993) Genetic differentiation of Texas Gulf Coast populations of the blue crab Callinectes sapidus. Mar Biol 117:227-233

Lambert WJ, Todd CD, Thorpe JP (2003) Genetic population structure of two intertidal nudibranch molluscs with contrasting larval types: temporal variation and transplant experiments. Mar Biol 142:461-471

Lee HJ, Boulding EG (2007) Mitochondrial DNA variation in space and time in the northeastern Pacific gastropod, Littorina keenae. Mol Ecol 16:3084-3103

Lenfant P, Planes S (2002) Temporal genetic changes between cohorts in a natural population of a marine fish, Diplodus sargus. Biol J Linn Soc 76:9-20

Li G, Hedgecock D (1998) Genetic heterogeneity, detected by PCRSSCP, among samples of larval Pacific oysters (Crassostrea gigas) supports the hypothesis of large variance in reproductive success. Can J Fish Aquat Sci 55:1025-1033
Liu JH (1994a) The ecology of the Hong Kong limpets Cellana grata (Gould, 1859) and Patelloida pygmaea (Dunker, 1860): reproductive biology. J Moll Stud 60:97-111

Liu JH (1994b) The ecology of the Hong Kong limpets Cellana grata (Gould, 1859) and Patelloida pygmaea (Dunker, 1860): distribution and population dynamics. J Moll Stud 60:55-67

Luikart G, Cornuet JM (1998) Empirical evaluation of a test for identifying recently bottlenecked populations allele frequency data. Conserv Biol 12:228-237

Lundy CJ, Rico C, Hewitt GM (2000) Temporal and spatial genetic variation in spawning grounds of European hake (Merluccius merluccius) in the Bay of Biscay. Mol Ecol 9:2067-2079

Maes GE, Pujolar JM, Hellemans B, Volckaert FAM (2006) Evidence for isolation by time in the European eel (Anguilla anguilla L.). Mol Ecol 15:2095-2107

Magalon H, Adjeroud M, Veuille M (2005) Patterns of genetic variation do not correlate with geographical distance in the reefbuilding coral Pocillopora meandrina in the South Pacific. Mol Ecol 14:1861-1868

McIlwain JL (2003) Fine-scale temporal and spatial patterns of larval supply to a fringing reef in Western Australia. Mar Ecol Prog Ser 252:207-222

Morgan SG (2001) The larval ecology of marine communities. In: Bertness MD, Baines SD, Hay ME (eds) Marine community ecology. Sinauer Associates Inc., Sunderland, pp 159-181

Ng WC, Chan MN, Slingsby G, Williams GA, Leung FCC (2009) Isolation and characterization of microsatellite markers from the limpet Cellana grata. Mol Ecol Resour 9:902-904

Ngan A (2006) Environmental stress and its implications for behavioural plasticity in foraging in Cellana grata. Unpublished $\mathrm{PhD}$ thesis, The University of Hong Kong, Hong Kong

Paetkau D, Slade R, Burden M, Estoup A (2004) Genetic assignment methods for the direct, real-time estimation of migration rate: a simulation-based exploration of accuracy and power. Mol Ecol 13:55-65

Pedersen EM, Hunt HL, Scheibling RE (2000) Temporal genetic heterogeneity within a developing mussel (Mytilus trossulus and M. edulis) assemblage. J Mar Biol Assoc UK 80:843-854

Peel D, Ovenden JR, Peel SL (2004) NeEstimator: software for estimating effective population size, Version 1.3. Queensland Government, Department of Primary Industries and Fisheries

Piry S, Alapetite A, Cornuet JM, Paetkau D, Baudouin L, Estoup A (2004) GENECLASS2: A software for genetic assignment and first-generation migrant detection. J Hered 95:536-539

Pujolar JM, Maes GE, Volckaert FAM (2006) Genetic patchiness among recruits in the European eel Anguilla anguilla. Mar Ecol Prog Ser 307:209-217

Rannala B, Mountain JL (1997) Detecting immigration by using multilocus genotypes. Proc Natl Acad Sci USA 94:9197-9201

Raymond M, Rousset F (1995) GENEPOP (version 1.2): population genetics software for exact tests and ecumenicism. J Hered $86: 248-249$

Raymond M, Vääntö RL, Thomas F, Rousset F, De Meeüs T, Renaud F (1997) Heterozygote deficiency in the mussel Mytilus edulis species complex revisited. Mar Ecol Prog Ser 156:225-237

Rice WR (1989) Analyzing tables of statistical tests. Evolution 43:223-225

Rose CG, Paynter KT, Hare MP (2006) Isolation by distance in the eastern oyster, Crassostrea virginica, in Chesapeake Bay. J Hered 97:158-170

Selkoe KA, Gaines SD, Caselle JE, Warner RR (2006) Current shifts and kin aggregation explain genetic patchiness in fish recruits. Ecology 87:3082-3094

Svensson CJ, Jenkins SR, Hawkins SJ, Myers AA, Range P, Paula J, O'Riordan RM, Aberg P (2004) Models of open populations with space-limited recruitment in stochastic environments:

\begin{tabular}{|c|c|c|c|c|}
\hline & Journal : Large 227 & Dispatch : & 12-10-2009 & Pages: $\mathbf{1 3}$ \\
\hline & $\begin{array}{l}\text { Article No. : } \mathbf{1 3 2 0} \\
\text { MS Code : } \quad \text { MABI-D-09-00254 }\end{array}$ & $\begin{array}{l}\square \mathrm{LE} \\
\boldsymbol{\sim}_{\mathrm{CP}} \\
\end{array}$ & & $\begin{array}{l}\square \\
\checkmark \text { TYPESET } \\
\text { DISK }\end{array}$ \\
\hline
\end{tabular}


relative importance of recruitment and survival in populations of Semibalanus balanoides. Mar Ecol Prog Ser 275:185-197

Takezaki N, Nei M (1996) Genetic distances and reconstruction of phylogenetic trees from microsatellite DNA. Genetics 144:389399

Turner TF, Wares JP, Gold JR (2002) Genetic effective size in three orders of magnitude smaller than adult census size in an abundant, estuarine-dependent marine fish (Sciaenops ocellatus). Genetics 162:1329-1339

Underwood AJ, Fairweather PG (1989) Supply-side ecology and benthic marine assemblages. Trends Ecol Evol 4:16-20

van Oosterhaut C, Hutchinson WF, Wills DPM, Shipley P (2004) MICRO-CHECKER: software for identifying and correcting genotyping errors in microsatellite data. Mol Ecol Notes 4:535538

Virgilio M, Abbiati M (2006) Temporal changes in the genetic structure of intertidal population of Hediste diversicolor (Polychaeta: Nereididae). J Sea Res 56:53-58

Waples RS (1989) A generalized approach for estimating effective population size from temporal changes in allele frequency. Genetics 121:379-391
Waples RS (1998) Separating the wheat from the chaff: Patterns of genetic differentiation in high gene flow species. J Hered 89:438-450

Weber LI, Hawkins LI (2006) Allozymic differentiation among geographically distant populations of Patella vulgata (Mollusca, Patellogastropoda). Hydrobiologia 553:267-275

Weetman D, Hauser L, Bayes MK, Ellis JR, Shaw PW (2006) Genetic population structure across a range of geographic scales in the commercially exploited marine gastropod Buccinum undatum. Mar Ecol Prog Ser 317:157-169

Weir BS, Cockerham CC (1984) Estimating $F$-statistics for the analysis of population structure. Evolution 38:1358-1370

Williams GA, Morritt D (1995) Habitat partitioning and thermal tolerance in a tropical limpet, Cellana grata. Mar Ecol Prog Ser 124:89-103

Yan Y, Chan BKK, Williams WA (2006) Reproductive development of the barnacle Chthamalus malayensis in Hong Kong: implications for the life-history patterns of barnacles on seasonal, tropical shores. Mar Biol 148:875-887

\begin{tabular}{|l|lll|} 
Journal : Large 227 & Dispatch : 12-10-2009 & Pages : 13 \\
Article No. : $\mathbf{1 3 2 0}$ & $\square$ LE & $\square$ TYPESET \\
& MS Code : MABI-D-09-00254 & $\sim_{\text {CP }}$ & $\checkmark$ DISK \\
\hline
\end{tabular}

